\title{
ACLIMATIZAÇÃO DE MUDAS MICROPROPAGADAS DE BANANEIRA SOB DIFERENTES CONDIÇÕES DE LUMINOSIDADE ${ }^{1}$
}

\author{
MARLON CRISTIAN TOLEDO PEREIRA², SILVIA NIETSCHE², ANDRÉ CABRAL FRANÇA³, CLAUDINÉIA \\ FERREIRA NUNES ${ }^{3}$, CYNTHIA DE LIMA³, VALDEIR DIAS GONÇALVES ${ }^{3}$, BÁRBARA PANICALLE SALLES ${ }^{3}$, \\ DANIELLLE LOURDES BATISTA MORAIS ${ }^{3}$, MAURO KOJI KOBAYASHI ${ }^{2}$
}

\begin{abstract}
RESUMO - O objetivo do presente trabalho foi avaliar a taxa de sobrevivência de mudas de bananeira micropropagadas, sob diferentes condições de aclimatização. Mudas de bananeira "Prata-Anã', obtidas por micropropagação, com 2-3 cm de comprimento, foram plantadas em bandejas contendo substrato comercial Plantmax. As bandejas contendo os tubetes foram colocadas sob estufins com cobertura plástica transparente, para aclimatização em diferentes condições de luminosidade. Os tratamentos foram compostos de: T1- Câmara de aclimatização sob cobertura em telhado de amianto; T2- Câmara de aclimatização sob telado, com 50 \% de sombreamento, e T3- Câmara de aclimatização coberta com papel tipo Kraft e sob telado, com $50 \%$ de sombreamento. O delineamento experimental foi inteiramente casualizado, com três tratamentos e setenta repetições. As plantas permaneceram por 15 dias nos referidos tratamentos, quando foi realizada a primeira avaliação. Aos 30 dias após o plantio, foi realizada a segunda avaliação. Foram avaliadas as características comprimento da muda, diâmetro do coleto, número de folhas completamente expandidas e porcentagem de pegamento. As características avaliadas foram submetidas à análise de variância, sendo os efeitos dos tratamentos comparados pelo teste de Tukey, a 5\% de probabilidade. Na primeira avaliação, observaram-se $100 \%$ de sobrevivência das plântulas nas três condições de luminosidade testadas. Aos trinta dias após o plantio em tubete, as plantas aclimatizadas em estufin sob telado com $50 \%$ de sombreamento apresentaram as maiores médias de comprimento, diâmetro e número de folhas, com 4,6 cm, 0,64 cm e 5,5 folhas, respectivamente.
\end{abstract}

Termos para indexação: Musa spp., viveiro de aclimatização, pegamento.

\section{ACCLIMATIZATION OF YOUNG BANANA PLANTS UNDER DIFFERENT CONDITIONS OF LUMINOSITY}

ABSTRACT - The present work aimed at evaluating the rate of survival of micro propagated young plants of banana under different acclimatization conditions. Young banana plants 'Prata Anã', from micro propagation, with 2-3 cm of length were planted in little tubes filled with the commercial substratum Plantmax. The trays with the little tubes were placed in small greenhouse with transparent plastic covering to acclimatization in different conditions of luminosity. The treatments were composed by: T1- Acclimatization chamber with covering of amianthus roof, T2- Acclimatization chamber under mesh, with $50 \%$ of shading and T3- Acclimatization chamber covered with paper type Kraft and under mesh, with $50 \%$ of shading. The experimental design was entirely randomized, with three treatments and seventy repetitions. The plants remained for 15 days in the related treatments, when the first evaluation was carried through. The second evaluation occurred at 30 days after planting. The evaluated characteristics were length of the young plants; diameter of point of connecting of root and stem, number of completely expanded leaf and percentage of establishment. These characteristics were submitted to the variance analysis, being the effect of the treatments compared by the Tukey test, at $5 \%$ of probability. In the first evaluation, were observed $100 \%$ of the plantlets survived at the three tested conditions of luminosity. At the thirtieth days after the plantation the plants acclimatized in chamber under mesh with $50 \%$ of shading, presented the greatest averages of length, diameter and number of leaves, with $4.6 \mathrm{~cm} ; 0.64 \mathrm{~cm}$ e 5.5 leaves, respectively.

Index terms: Musa spp., nursery of acclimatization, establishment.

\section{INTRODUÇÃO}

De acordo com a FAO (2002), das 579 milhões de toneladas de frutas produzidas no ano de 2002, a banana representou 97,3 milhões $(16,8 \%)$, destacando-se como a principal fruta no contexto mundial, seguido pela laranja, uva, maçã e manga. De acordo com o IBGE (2003), depois da laranja, a maior produção brasileira em 2003 foi a de banana, com 6,4 milhões de toneladas em 514.647 ha. Esta produção representa $6,6 \%$ do total de banana produzido, colocando o Brasil em segundo lugar no ranking mundial, perdendo apenas para a Índia, com 16 milhões de toneladas. O norte de Minas Gerais destaca-se como uma das principais regiões produtoras de banana no Brasil, adotando alta tecnologia de produção e obtendo altas produtividades, em função principalmente das excelentes condições edafoclimáticas, com alta temperatura e baixa umidade relativa, associada à prática da irrigação (Casassanta, 2001). De acordo com Alves (1997), a propagação da bananeira é por meio de mudas desenvolvidas a partir de gemas do seu caule subterrâneo ou rizoma. No Brasil e em outros países produtores de banana, a grande maioria dos plantios de bananeiras ainda são realizados utilizando mudas provenientes de bananais já existentes, apesar de alguns produtores mais tecnificados já adotarem mudas advindas de cultivo in vitro. O sistema de propagação convencional mediante mudas é lento e permite a disseminação de doenças como o Mal-do-Panamá (Fusarium oxysporium f. sp. cubense), Moko (Haustonia solanacearum), Sigatoka-negra (Mycosphaerella fijiensis var. difformis), nematóides e a broca-do-rizoma (Cosmopolites sordidus) que são, atualmente, os fatores limitantes à expansão da cultura.

A micropropagação da bananeira é realizada em condições controladas de laboratório, proporciona a mais alta eficiência dentre os métodos de multiplicação de mudas de bananeira, apresentando um rendimento de 150 a 300 mudas por matriz, num período de 6 a 8 meses (Borges et al., 1997). Outras vantagens estão associadas ao método, podendo ser ressaltadas as seguintes: (1) as mudas são produzidas rapidamente em espaço físico reduzido; (2) apresentam alta qualidade fitossanitária; (3) são fáceis de serem transportadas, e (4) proporcionam uniformidade nos tratos culturais e colheita no primeiro ciclo da cultura (Borges et al., 1997).

A possibilidade de se utilizar no plantio mudas micropropagadas é atualmente a melhor alternativa para se conseguir material de qualidade genética e fitossanitária garantida. Embora apresente alguns problemas, como tamanho reduzido, necessitando de uma etapa intermediária entre a produção da muda pelo laboratório e o seu plantio em campo. Deve-se mencionar, ainda, o seu elevado custo inicial, o que poderá representar mais de $25 \%$ do total do custo de implantação (Batista, 1996).

A aclimatização de mudas é o processo pelo qual plantas produzidas em condições in vitro são transferidas para um ambiente com as condições climáticas naturais. Essas novas condições devem ser passadas às plantas progressivamente, de forma que elas sofram menor estresse, que possam culminar em injúrias profundas ou até mesmo em

\footnotetext{
${ }^{1}$ (Trabalho 029/2005). Recebido: 23/02/2005. Aceito para publicação: 05/08/2005.

${ }^{2}$ Eng $^{\circ}$ Agr $^{\circ}$., Dr., Prof., Dep. Ciências Agrárias,UNIMONTES, Caixa Postal 91, CEP39440-000. Janaúba, MG. E-mail: marlonsilvia@nortecnet.com.br.

${ }^{3}$ Estudantes do Curso de Agronomia da UNIMONTES.
} 
morte (Brainerd \& Fuchigami, 1981). Esse processo representa uma etapa importante dentro de um programa onde se trabalha com cultura de tecidos, sendo que, em alguns casos, chega a ser o fator limitante no processo de micropropagação (Grattapaglia \& Machado, 1990). O principal obstáculo encontrado na aclimatização é o baixo rendimento encontrado, ou seja, produz-se um número grande de plantas micropropagadas em sala de crescimento, mas, quando são transferidas para as condições ambientais externas, ocorrem perdas significativas. Desta forma, poucas mudas estarão em condições de serem levadas ao campo. Diante disso, cada planta apta e em condições de plantio apresentará um alto custo, que inevitavelmente será repassado para o consumidor final (Pierik, 1988).

O objetivo do presente trabalho foi avaliar a aclimatização de mudas micropropagadas de bananeira cultivar Prata-Anã, irrigadas com o uso de aspersores de cotonete, sob diferentes condições de luminosidade, na região norte de Minas Gerais.

\section{MATERIAL E MÉTODOS}

O experimento foi realizado no Laboratório de Cultura de Tecidos e Células Vegetais e no viveiro de aclimatização de mudas de bananeira, localizados no Câmpus da Universidade Estadual de Montes Claros UNIMONTES, município de Janaúba-MG. Rizomas de bananeira tipo chifrinho, cv. Prata-Anã, provenientes do matrizeiro, foram retirados e encaminhados ao laboratório. Em condições assépticas, estes foram desinfestados e implantados em meio de cultura. Do estabelecimento ao $5^{\circ}$ subcultivo de multiplicação, utilizou-se do meio MS (Murashige \& Skoog, 1962), suplementado com $5 \mathrm{mg} / \mathrm{l}$ de benzilaminopurina (BAP) e 30 $\mathrm{g} / \mathrm{L}$ de sacarose, geleificado com $7 \mathrm{~g} / \mathrm{L}$ de ágar. No enraizamento, utilizouse de um meio com $50 \%$ dos sais minerais do MS, adicionado de $15 \mathrm{~g} / \mathrm{L}$ de sacarose e $7 \mathrm{~g} / \mathrm{L}$ de ágar, sem BAP. Durante as fases de multiplicação e enraizamento, as mudas foram incubadas em sala de crescimento $\left(27^{\circ} \mathrm{C} \pm\right.$ $2^{\circ} \mathrm{C}$ ), a um fotoperíodo de 16 horas, com uma intensidade luminosa de 50 umol. $\mathrm{m}^{-2} . \mathrm{S}^{-1}$, obtidas de lâmpadas fluorescentes frias. Após a fase de enraizamento in vitro, quando as mudas atingiram comprimento de 2,5 $\mathrm{cm}$, cartucho definido, três folhas e raízes já formadas, procedeu-se à lavagem das raízes e ao acondicionamento das plantas em bandejas com água por um período de 96 horas. Em seguida a este período de préaclimatização das mudas em laboratório, foi efetuado o plantio no dia 16 de abril de 2004. Foram utilizados tubetes de $0,05 \mathrm{dm}^{3}$ preenchidos com substrato comercial Plantmax. Após o plantio, bandejas contendo os tubetes foram colocadas sob estufins com cobertura plástica transparente, para aclimatização em diferentes condições de luminosidade.

Os estufins foram mantidos suspensos por cavaletes, a quarenta e dois centímetros de altura do solo. Um sistema de irrigação com uso de aspersores de cotonete foi utilizado para manter condição de alta umidade relativa, em média de $90 \%$. Os aspersores foram construídos com as hastes de cotonetes de ouvido, vedando uma das extremidades e fazendo um corte transversal parcial próximo à extremidade vedada, no qual a água era aspergida (Rodrigues, 2004). O cotonete apresentou vazão média de 23,5 litros por hora. Uma mangueira de polietileno preto de $1 / 2$ polegada foi fixada na parte central e superior de cada estufim, na qual foram inseridos os cotonetes a cada $0,42 \mathrm{~m}$. A irrigação foi constituída por cinco turnos de rega $(7 ; 10 ; 13 ; 15$ e 17 horas), com duração de dez minutos em cada horário, aplicando-se uma lâmina de irrigação de $8,2 \mathrm{~L} / \mathrm{H} / \mathrm{m}^{2}$. Diariamente, ao final da tarde, foram registradas no interior dos estufins as temperaturas máxima e mínima. Os tratamentos foram compostos de: T1- Estufim de aclimatização sob cobertura em telhado de amianto (totalmente sombreado); T2- Estufim de aclimatização sob telado, com 50\% de sombreamento, e T3- Estufim de aclimatização coberto por papel tipo Kraft, totalmente sombreado e sob telado, com $50 \%$ de sombreamento. O delineamento experimental foi inteiramente casualizado, com três tratamentos e setenta repetições, com uma planta útil por parcela. As plantas permaneceram por 15 dias nos referidos tratamentos. Em seguida, os estufins foram retirados, e as plantas de todos os tratamentos foram transferidas para as condições sob telado com $50 \%$ de sombreamento, sendo transplantadas para sacolas de polietileno com dimensões de 14 $\mathrm{cm} \times 5 \mathrm{~cm}$, contendo o mesmo substrato. Neste momento, foram realizadas as primeiras avaliações para as características comprimento, diâmetro do coleto da muda, número de folhas completamente expandidas e porcentagem de pegamento. As mudas foram mantidas diretamente sob telado com $50 \%$ de sombreamento por mais 15 dias após o transplantio, momento em que foi realizada uma segunda avaliação, correspondendo aos trinta dias após o plantio em tubetes. As características avaliadas foram submetidas à análise de variância, sendo os efeitos dos tratamentos comparados pelo teste de Tukey, a 5\% de probabilidade.

\section{RESULTADOS E DISCUSSÃO}

Na primeira avaliação, aos 15 dias após o plantio em tubetes, observou-se $100 \%$ de pegamento das mudas de bananeira em todos os tratamentos (Tabela 1). Estudos conduzidos com a micropropagação da bananeira cultivar Terra, provenientes do cultivo em sistema de biorreatores, obtiveram em torno de $70 \%$ de mudas aclimatizadas (Lemos et al., 2001). De acordo com Sutter (1988), quando transferidas para aclimatização, plantas enraizadas in vitro são submetidas a uma condição de alta transpiração que, associada à alta condutividade hídrica, provoca baixa funcionalidade ou ausência de controle sobre o fechamento dos estômatos. Essa condição provoca altas taxas de mortalidades, o que não foi observado neste trabalho. Em algumas espécies, na fase de aclimatização, é necessária a utilização de câmaras compostas por caixas cobertas com lâminas de vidro, com temperatura de $27 \pm 2^{\circ} \mathrm{C}$, fotoperíodo de 16 horas e intensidade luminosa de $75 \mu \mathrm{mol} . \mathrm{m}^{-2} . \mathrm{s}^{-1}$ (Pedrotti, 1993).

No presente trabalho, foram observadas temperaturas superiores a $36^{\circ} \mathrm{C}$ no interior das câmaras de nebulização. Estes resultados indicam que as mudas micropropagadas de bananeira 'Prata-Anã' não apresentam grande sensibilidade às altas temperaturas, provavelmente o fator de maior relevância durante o processo de aclimatização esteja diretamente relacionado com a umidade relativa.

De acordo com Oliveira \& Melo (1998), esta primeira fase de aclimatização é conhecida por berçário, momento em que as mudas necessitam de condições especiais de umidade acima de $80 \%$, temperatura média de 26 ÚC e sombreamento mínimo de $60 \%$. Grout (1988) ressalta que as condições ambientais sob as quais ocorre o cultivo in vitro, no que se refere à composição do meio de cultura e do ar no interior dos recipientes, bem como quanto à luminosidade e a temperatura fazem com que as plantas provenientes da micropropagação apresentem algumas características peculiares, como a das folhas, especialmente no que se refere à sua anatomia e isso poderá refletir sobre a perda de água quando da aclimatização (Grout, 1988). Outro fator que pode influenciar no pegamento, é a ausência da cera epicuticular que reveste o tecido foliar. Plantas cultivadas in vitro perdem água rapidamente pela transpiração quando são transferidas a um ambiente seco na condição ex vitro (Sutter,

TABELA 1 - Comprimento, diâmetro, porcentagem de mortalidade e número de folhas em plantas de bananeira 'Prata-Anã' sob três condições de luminosidade aos 15 dias. Janaúba-MG, 2004.

\begin{tabular}{ccccc}
\hline Tratamentos & Comprimento das mudas $(\mathrm{cm})$ & Diâmetro das mudas $(\mathrm{cm})$ & Porcentagem de mortalidade $(\%)$ & Número de folhas \\
\hline 1 & $2,79 \mathrm{a}$ & $0,49 \mathrm{a}$ & $0,0 \mathrm{a}$ & $3,71 \mathrm{a}$ \\
2 & $2,63 \mathrm{a}$ & $0,46 \mathrm{a}$ & $0,0 \mathrm{a}$ & $4,51 \mathrm{a}$ \\
3 & $2,83 \mathrm{a}$ & $0,44 \mathrm{a}$ & $0,0 \mathrm{a}$ & $4,10 \mathrm{a}$ \\
\hline Média & 2,75 & 0,46 & 0,0 & 4,11 \\
\hline
\end{tabular}

${ }^{1}$ Médias seguidas da mesma letra, na coluna, não diferem estatisticamente entre si, pelo teste de Tukey, a 5\% de probabilidade.

${ }^{2}$ Tratamentos: $1=$ Estufim de aclimatização protegida com telhado de amianto; $2=$ Estufim de aclimatização sob telado com $50 \%$ de sombreamento; $3=$ Estufim de aclimatização coberta por papel do tipo Kraft e sob telado com $50 \%$ de sombreamento. 
TABELA 2 - Comprimento, diâmetro, porcentagem de mortalidade e número de folhas em plantas de bananeira 'Prata-Anã' sob telado aos 30 dias. Janaúba-MG, 2004.

\begin{tabular}{|c|c|c|c|c|}
\hline Tratamentos & Comprimento das mudas $(\mathrm{cm})$ & Diâmetro das mudas (cm) & Porcentagem de mortalidade (\%) & Número de folhas \\
\hline 1 & $3,64 \mathrm{~b}$ & $0,56 \mathrm{~b}$ & $1,43 \mathrm{a}$ & $4,88 \mathrm{~b}$ \\
\hline 2 & $4,59 \mathrm{a}$ & $0,64 \mathrm{a}$ & $1,43 \mathrm{a}$ & $5,50 \mathrm{a}$ \\
\hline 3 & $3,23 \mathrm{c}$ & $0,54 \mathrm{~b}$ & $1,43 \mathrm{a}$ & $4,73 \mathrm{~b}$ \\
\hline Média & 3,82 & 0,58 & 1,43 & 5,04 \\
\hline
\end{tabular}

${ }^{1}$ Médias seguidas da mesma letra, na coluna, não diferem estatisticamente entre si, pelo teste de Tukey, a 5\% de probabilidade.

${ }^{2}$ Tratamentos: $1=$ Estufim de aclimatização protegida com telhado de amianto; $2=$ Estufim de aclimatização sob telado com 50\% de sombreamento; $3=$ Estufim de aclimatização coberta por papel do tipo Kraft sob telado com $50 \%$ de sombreamento.

1988). Na aclimatização, a planta começa a ativar seus fotossistemas 1 e 2 e a formação de cloroplastos, entre outros fatores fisiológicos, para que todo este processo seja perfeito e a planta se constitua de todas as suas estruturas funcionais, essenciais para seu desenvolvimento (Wetzstein $\&$ Sommer, 1982).

Para tanto, a fase de pré-aclimatização não pode ser omitida, pois as novas condições devem ser repassadas às plantas de forma progressiva.

Não foram detectadas diferenças significativas para nenhuma das características avaliadas aos 15 dias após o plantio em tubetes, indicando que as diferentes condições de luminosidade não influenciaram no crescimento das plantas. Os valores médios para as características de comprimento, diâmetro e número de folhas foram $2,75 \mathrm{~cm}, 0,46 \mathrm{~cm}$ e 4,11 folhas, respectivamente (Tabela 1).

Trinta dias após o plantio em tubetes, foi observada porcentagem de mortalidade de $1,43 \%$ para os três tratamentos (Tabela 2). Este pode ser considerado um índice muito baixo, principalmente por esta ser uma fase de grandes alterações em termos de temperatura e umidade relativa. Lisei de Sá \& Braga (2002), avaliando protocolos de multiplicação in vitro da bananeira 'Prata-Anã', não relataram perdas de mudas durante o processo de aclimatização, ressaltam que o padrão ideal para iniciar o processo de aclimatização deve ocorrer quando as mesmas atingirem um mínimo de $30 \mathrm{~mm}$ de comprimento. Pedrotti \& Voltolini (2001), trabalhando com enraizamento ex vitro e aclimatização do porta-enxerto de macieira 'M-9', obtiveram sobrevivência de 70 a 95\% aos quarenta e cinco dias em casa de vegetação com temperatura de $25 \pm 4^{\circ} \mathrm{C}$ e irrigação por aspersão. Provavelmente, as plantas que já sofreram o estresse inicial na fase de berçário, apresentaram melhores condições fisiológicas de suportar a segunda fase de aclimatização em sistema de telado.

Na segunda avaliação, ao 30 dias após plantio, foram detectadas diferenças significativas para todas as características (Tabela 2). Os melhores resultados foram obtidos a partir das plantas provenientes do estufim acondicionado diretamente sob telado com $50 \%$ de sombreamento, diferindo significativamente das plantas provenientes dos outros tratamentos, com médias de 4,59 $\mathrm{cm}, 0,64 \mathrm{~cm}$ e 5,50, referentes ao comprimento, diâmetro e número de folhas, respectivamente (Tabela 2). Neste período final de 15 dias em condições sob telado, observou-se um crescimento de $1,76 \mathrm{~cm}$ na altura das plantas. Para a característica de diâmetro do coleto e número de folhas, foi observada a mesma tendência, com acréscimo de $0,15 \mathrm{~cm}$ e 0,99 folhas, respectivamente.

\section{CONCLUSÕES}

Mudas de bananeira 'Prata-Anã', provenientes do cultivo in vitro podem ser aclimatizadas diretamente em telado a $50 \%$ de sombreamento, sob estufim com cobertura plástica, em sistema de irrigação por nebulização, com temperatura média de $30^{\circ} \mathrm{C}$.

\section{REFERÊNCIAS}

ALVES, E.J. A cultura da banana: aspectos técnicos, socioeconômicos e agroindustriais. Brasília: Embrapa-SPI/Cruz das Almas: EmbrapaCNPMF, 1997.585p

BATISTA, L.A. Métodos de multiplicação de mudas matrizes de bananeira (Musa spp.), obtidas por cultura de meristemas. 1996. 51f. Dissertação (Mestrado em Fitotecnia) - Universidade Federal de Lavras, Lavras, 1996.

BORGES, A.L.; ALVES, E. J.; SILVA, S.O.; SOUZA, L. DA S. O cultivo da banana. Cruz das Almas: EMBRAPA-CMPMF, 1997. 109p. (Circular Técnica, 27).

BRAINERD, K.E.; FUCHIGAMI, L.H. Acclimatization of aseptically cultured plants to low relatively humidity. Journal of the American Society of Horticultural Science, Alexandria, v. 106, n. 4, p. 515$518,1981$.

CASASSANTA, N.M. A bananicultura do Norte de Minas e seus impactos na economia regional. In: SIMPÓSIO NORTE MINEIRO SOBRE A CULTURA DA BANANA, 1., 2001, Nova PorteirinhaMG. Anais... Montes Claros: Editora UNIMONTES, 2001.p. 180187.

FAO. Disponível em:<http://apps.fao.org>. Acesso em: 2002.

GRATTAPAGLIA, D.; MACHADO, M.A. In: TORRES, A.C.; CALDAS, L.S. Técnicas e aplicações da cultura de tecidos de plantas. Brasília: ABCTP/EMBRAPA-CNPH, 1990. p.99-170.

GROUT, B.W.W. Photosynthesis of regenerated plantlets "in vitro", and the stresses of transplanting. Acta Horticulturae, Wageningen, n.230, p.129-155, 1988 .

IBGE - Instituto Brasileiro de Geografia e Estatística. Anuário Estatístico do Brasil. Rio de Janeiro, 2003. v.54, cap. 3, p.21.

LEMOS, E.E.P.; FERREIRA, M.S.; ALENCAR, L.M.; OLIVEIRA, J.G.L.; MAGALHÃES, V.S. Micropropagação de clones de banana CV. Terra em biorreator de imersão temporária. Revista Brasileira de Fruticultura, Jaboticabal, v.23, n.3, p.482-487, 2001.

LISEI DE SÁ, M.E.; BRAGA, M.F. Avaliação de protocolos para obtenção de mudas micropropagadas de bananeira CV. Prata-Anã (Subgrupo AAB). Revista Brasileira de Fruticultura, Jaboticabal, v. 24, n. 1, p. 236-239, 2002.

MURASHIGE, T.; SKOOG, F. A revised medium for rapid growth and bioassays with tobacco tissue cultures. Physiology Plantarum, Copenhagem, v.15, p.473-497, 1962.

OLIVEIRA, R.P.; MELO, N.F. Produção comercial de mudas de bananeira em laboratórios de cultura de tecidos. Brasília: EMBRAPA, 1998. (Biotecnologia em Foco, 11)

PEDROTTI, E.L. Etude de i'organogènese in vitro à part de racines, de felhies et embryons zygotiques de merisier (Prunus avium L.). 1993. 167f. Dissertação (Doutorado em Fisiologia Vegetal)Université d' Orléans, Orléans, França, 1993.

PEDROTTI, E.L.; VOLTOLINI, J.A. Enraizamento ex vitro e aclimatização do porta-enxerto de macieira ' M.9'. Revista Brasileira de Fruticultura, Jaboticabal, p.234-239, 2001.

PIERIK, R.L.M. Handicaps for the large scale commercial application of micropropagation. Acta Horticulturae, Wageningen, 230, p.63-61, 1988.

RODRIGUES, W. P. O círculo da vida. Globo Rural, São Paulo, n.224, p.68-73, 2004

SUTTER, E. Stomatal and cuticular water loss from apple, cherry, and sweet gum plants after removal in vitro culture. Journal of American Society for Horticultural Science, Alexandria, v.113, n. 2, p. 234238,1988

WETZSTEIN, H.Y.; SOMMER, H.E. Leaf anatomy of tissue-cultured Hiquidambar styraciflua (Hamamelidaceae) during acclimatization. American Journal of Botany, Columbus, v.69, n.10, p.1579-1586, nov-dec,1982. 